\title{
Sudden Cardiac Arrest and Cardiopulmonary Resuscitation with Automated External Defibrillator in the Austrian Mountains: A Retrospective Study
}

\author{
Mathias Ströhle, Anna Vögele, ${ }^{2}$ Paul Neuhauser, ${ }^{1}$ Simon Rauch, ${ }^{2}$ Hermann Brugger, ${ }^{2}$ and Peter Paal ${ }^{3}$
}

\begin{abstract}
Ströhle, Mathias, Anna Vögele, Paul Neuhauser, Simon Rauch, Hermann Brugger, and Peter Paal. Sudden cardiac arrest and cardiopulmonary resuscitation with automated external defibrillator in the Austrian mountains: A retrospective study. High Alt Med Biol. 20:392-398, 2019.

Background: Few data exist on the likelihood of surviving sudden cardiac arrest in the mountains. The aim of this study was to analyze the epidemiology and outcomes of patients suffering sudden cardiac arrest and undergoing cardiopulmonary resuscitation (CPR) with automated external defibrillator (AED) in the Austrian mountains.

Materials and Methods: We analyzed all cardiac arrest cases in the Austrian mountains reported in the nationwide Austrian Alpine Police database from October 26, 2005, to December 31, 2015. To obtain information on outcomes, these patient data were manually merged with patient data from the main Austrian referral center for mountain emergencies, Innsbruck Medical University Hospital.

Results: Overall, 781 cases of sudden cardiac arrest in the Austrian mountains were recorded. In 136 cases (17\%), CPR with AED was attempted. The most frequent activities at the time of sudden cardiac arrest were hiking $(n=63,46 \%)$ and skiing or snowboarding $(n=44,32 \%)$. In the nationwide Austrian Alpine Police database, only $4(3 \%)$ patients survived, whereas in the Innsbruck Medical University Hospital database, there were seven survivors who received CPR and AED. All survivors had received immediate CPR with an AED. Five patients had good neurological outcome (cerebral performance category 1-2).

Conclusions: In the Austrian mountains, CPR was attempted in less than $20 \%$ of sudden cardiac arrest cases. The few that survived had received immediate CPR with an AED. To better understand the circumstances and outcome of sudden cardiac arrest in the mountains, out-of hospital and in-hospital data should be linked.
\end{abstract}

Keywords: cardiac arrest; cardiopulmonary resuscitation; defibrillation; emergency medicine; mountain medicine

\section{Introduction}

$\mathbf{T}$ HE AUSTRIAn AlPs are a popular destination for both locals and tourists from all over the world. The wide range of outdoor sports possibilities, including downhill skiing, ski mountaineering, snowboarding, hiking, climbing, mountain biking, and paragliding, is outstanding. The number of visitors to Austria and other mountainous areas rises steadily. While 2013 saw 43 million tourists in Tyrol, Austria's most visited state, by 2017 , the number had risen to 47.5 million.
In addition to the pleasurable aspects, mountain areas entail various risks for visitors and often pose difficult challenges for medical staff and mountain rescue teams. An analysis performed by the Austrian Alpine Safety Board shows that in the summer season, 2016, 131 fatal mountain accidents occurred in Austria. Mountain accidents are considered to be those classically caused by carelessness, fatigue, or a second party, as well as accidents or events that entail medical intervention. These also include the most serious medical emergencyprimary cardiac arrest, which is defined as an unexpected, nontraumatic death within 1 hour of the onset of symptoms

\footnotetext{
${ }^{1}$ Department of General and Surgical Critical Care Medicine, Medical University of Innsbruck, Innsbruck, Austria.

${ }^{2}$ Institute of Mountain Emergency Medicine, EURAC Research, Bolzano, Italy.

${ }^{3}$ Department of Anaesthesiology and Intensive Care Medicine, Paracelsus Medical University Salzburg, Hospitallers Brothers Hospital, Salzburg, Austria.
} 
(Burtscher et al., 2001). More than half $(n=76,58 \%)$ of the fatalities in summer 2016 occurred in hikers, and about half of them $(n=35,46 \%)$ were due to sudden cardiac arrest.

One demographic development in industrialized countries is an increase in elderly people in mountain regions, who are more likely to have a prior history of cardiovascular disease than are younger people (Faulhaber et al., 2007). Cardiovascular disease in general is the leading cause of death in Europe with 4.1 million deaths per year. Nearly half of all deaths are related to coronary heart disease, which can cause acute myocardial infarction and sudden cardiac arrest (Nichols et al., 2013).

Up to $60 \%$ of the elderly have cardiac conditions that increase the risk for sudden cardiac arrest (Hackett and Roach, 2001). Immediate cardiopulmonary resuscitation (CPR), ideally followed quickly by the use of an automated external defibrillator (AED), is key for neurologically intact survival (Perkins et al., 2015). AEDs are increasingly available in mountain areas (e.g., in lodges, cable car, and chairlift stations). Initiatives by medical societies, emergency and mountain rescue teams, are raising awareness for the benefits of and knowledge on how to perform CPR and use an AED in cardiac arrest (Elsensohn et al., 2006; Wallner et al., 2018).

Few case reports document successful use of AEDs in the mountains (Lienhart et al., 2005, 2006; Boehringer and Tilney, 2015; Yanagawa et al., 2017). The aim of this study was to analyze the epidemiology and outcomes of patients suf- fering sudden cardiac arrest and undergoing CPR with AED in the Austrian mountains. No study that analyzes the outcome of CPR with AED use in mountain areas at a national level has been conducted previously.

\section{Materials and Methods}

This was a retrospective epidemiological study. It was approved by the Ethics Committee of the Medical University of Innsbruck (AN4757 315/4.4) and registered with Clinical Trials under No. NCT03405467. We analyzed anonymized data from the Austrian Alpine Police, which are collected in the registry of the Austrian Alpine Safety Board. We extracted all emergency cases with sudden cardiac arrest and CPR from October 26, 2005 (when the digital registry was initiated), to December 31,2015 , by conducting a full text search query for "cardiopulmonary resuscitation" and "cardiovascular disorders.",

To analyze the outcome of CPR and AED use in the Austrian Alps, the Austrian Alpine Police data and the data from the hospital information system of Innsbruck Medical University Hospital were cross-checked case by case. Corresponding cases were manually merged. The hospital information system was also searched for potential cases. The most important aspects of the various data acquisition steps and data analysis are depicted in Figure 1. For the merged cases, the accident and the in-hospital course were described.

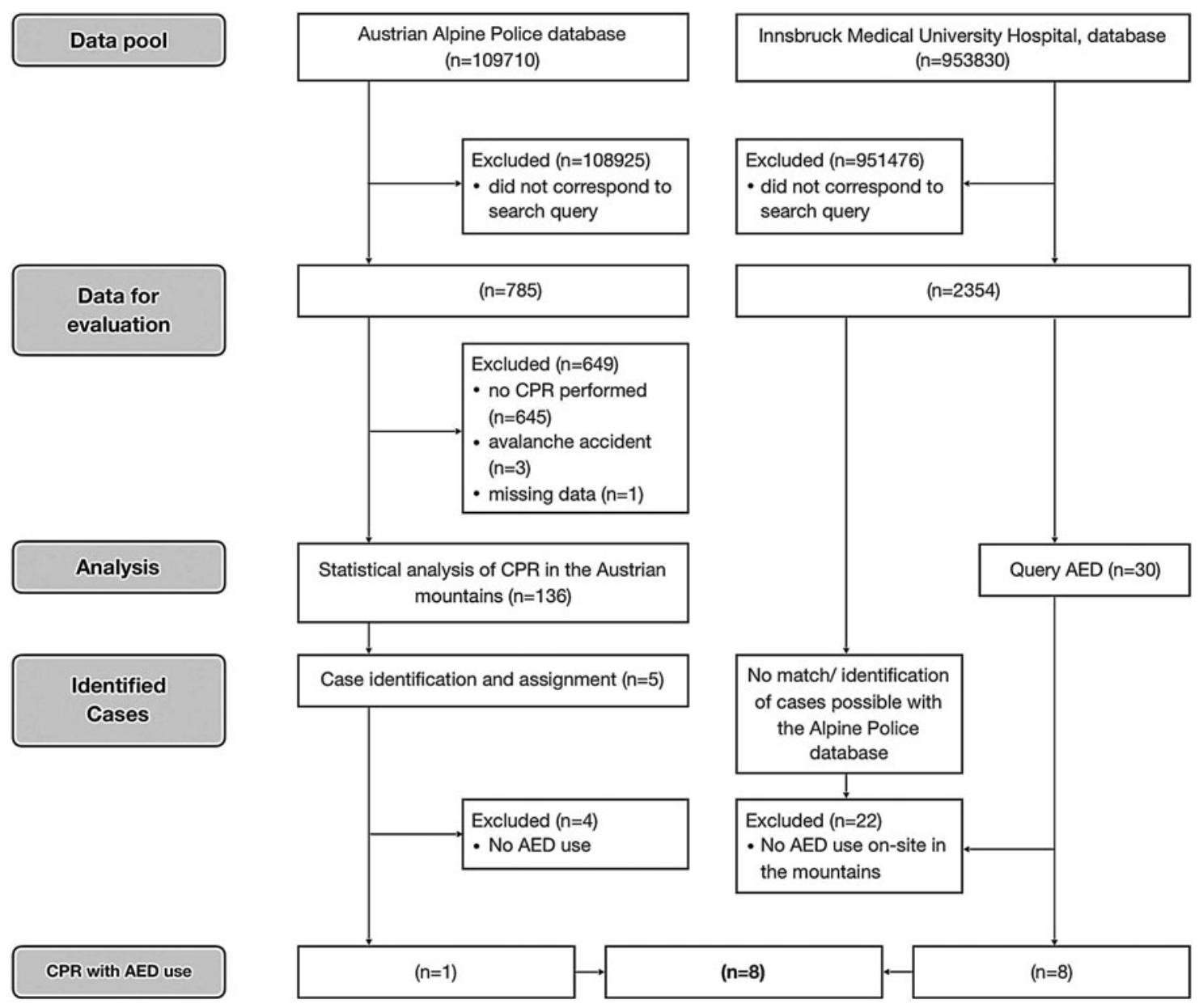

FIG. 1. Selection of cases meeting inclusion criteria. 
Table 1. Cerebral Performance Category, Classification of Neurological Outcome ${ }^{\mathrm{a}}$

\begin{tabular}{|c|c|}
\hline$C P C$ & Good outcome \\
\hline 1 & $\begin{array}{l}\text { Conscious and alert with normal function or only } \\
\text { slight disability }\end{array}$ \\
\hline 2 & Conscious and alert with moderate disability \\
\hline
\end{tabular}

Bad outcome

$\begin{array}{ll}3 & \text { Conscious with severe disability } \\ 4 & \text { Comatose or persistent vegetative state } \\ 5 & \text { Brain dead or death from other causes }\end{array}$

${ }^{\mathrm{a}}$ Ajam et al., 2011.

$\mathrm{CPC}$, cerebral performance category.

The information was obtained from emergency records, specialist consultation reports, and discharge letters. Neurological outcome was categorized according to the Cerebral Performance Category (Edgren et al., 1994; Ajam et al., 2011) (Table 1).

The inclusion criterion was sudden cardiac arrest in the mountains at any age. Exclusion criteria were no sudden cardiac arrest and no CPR performed at all (Supplementary Data S1).

Avalanche victims were excluded from this study, as the mechanism at work in such cases is asphyxia. For these special cases of CPR in the mountains, special registers and specific guidelines already exist (Brugger et al., 2013; Kottmann et al., 2017). Data were collected and analyzed using Microsoft Excel, version 2010, and IBM SPSS Statistics, version 21.0.

\section{Results}

A total of 785 cases of cardiac arrest were found. In 136 cases of cardiac arrest, CPR was performed (17\%, Fig. 2). Most patients $(n=125,92 \%)$ were male.

The youngest patient was 2 years old and the oldest was 88 years old; median age was 60 years. In half of the cases in which CPR was performed in the mountains, people were 5170 years of age $(n=73,54 \%)$ whereas most were $41-80$ years of age $(n=116,85 \%)$.

CPR was most commonly performed in summer and in winter (Fig. 3). Before cardiac arrest, $46 \%(n=63)$ of the patients were hiking (i.e., walking on well-marked trails of easy to moderate difficulty) or mountaineering (more challenging, a more technical variation that takes people to higher peaks). Sudden cardiac arrest occurred three times more often during the ascent than during the descent. In $32 \%(n=44)$, sudden cardiac arrest occurred when skiing or snowboarding, in $4 \%(n=6)$ when cross-country skiing, and in another $4 \%$ $(n=6)$ when ski mountaineering. The remaining 12\% $(n=17)$ of cases were divided among hunting, working, mountain biking, riding a ski lift, and rock climbing.

Of all sudden cardiac arrests in the mountains, 94 (69\%) cases occurred in Austria's three westernmost states Tyrol, Salzburg, and Vorarlberg. The main cause of cardiac arrest was an underlying cardiac condition in 129 (95\%) persons. It was mainly during periods of physical exertion that cardiac arrest occurred (Fig. 4).

Most cases $(n=84,62 \%)$ occurred at a moderate altitude between 1000 and 2000 meters. The remaining cases occurred almost equally at lower $(n=24,18 \%)$ and higher altitudes $(n=20,15 \%)$. Nationwide, we found only 4 patients (3\%) in whom CPR was performed and who survived the cardiac arrest. Three of the accidents with survivors occurred in Tyrol. In the registry of the Austrian Alpine Safety Board, we identified one patient who was resuscitated with an AED and subsequently treated at Innsbruck Medical University Hospital. In a second step, a full text search of the hospital information system of Innsbruck Medical University Hospital resulted in additional seven cases of alpine CPR with AED use, giving a total of $8(6 \%)$ cases in the two databases. Figure 1 shows the selection of cases meeting inclusion criteria.

Seven of the patients treated at Innsbruck Medical University Hospital survived cardiac arrest, five in good neurological condition with cerebral performance category 1 or 2 . All survivors had received CPR and defibrillation with AED

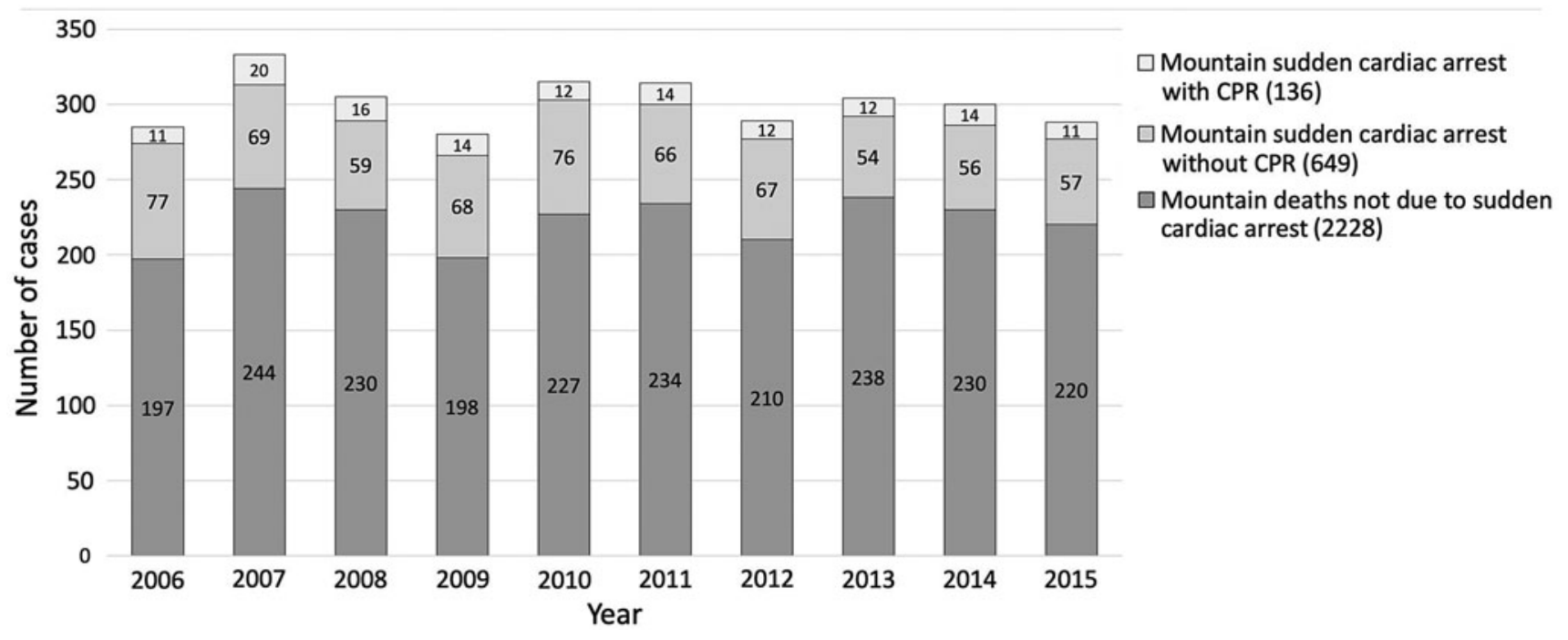

FIG. 2. Nationwide frequency of mountain fatalities in the years 2006-2015: mountain sudden cardiac arrest with CPR $(n=136)$, mountain sudden cardiac arrest without CPR $(n=649)$, and deaths in Austrian mountains not due to sudden cardiac arrest $(n=2228)$. CPR, cardiopulmonary resuscitation. 


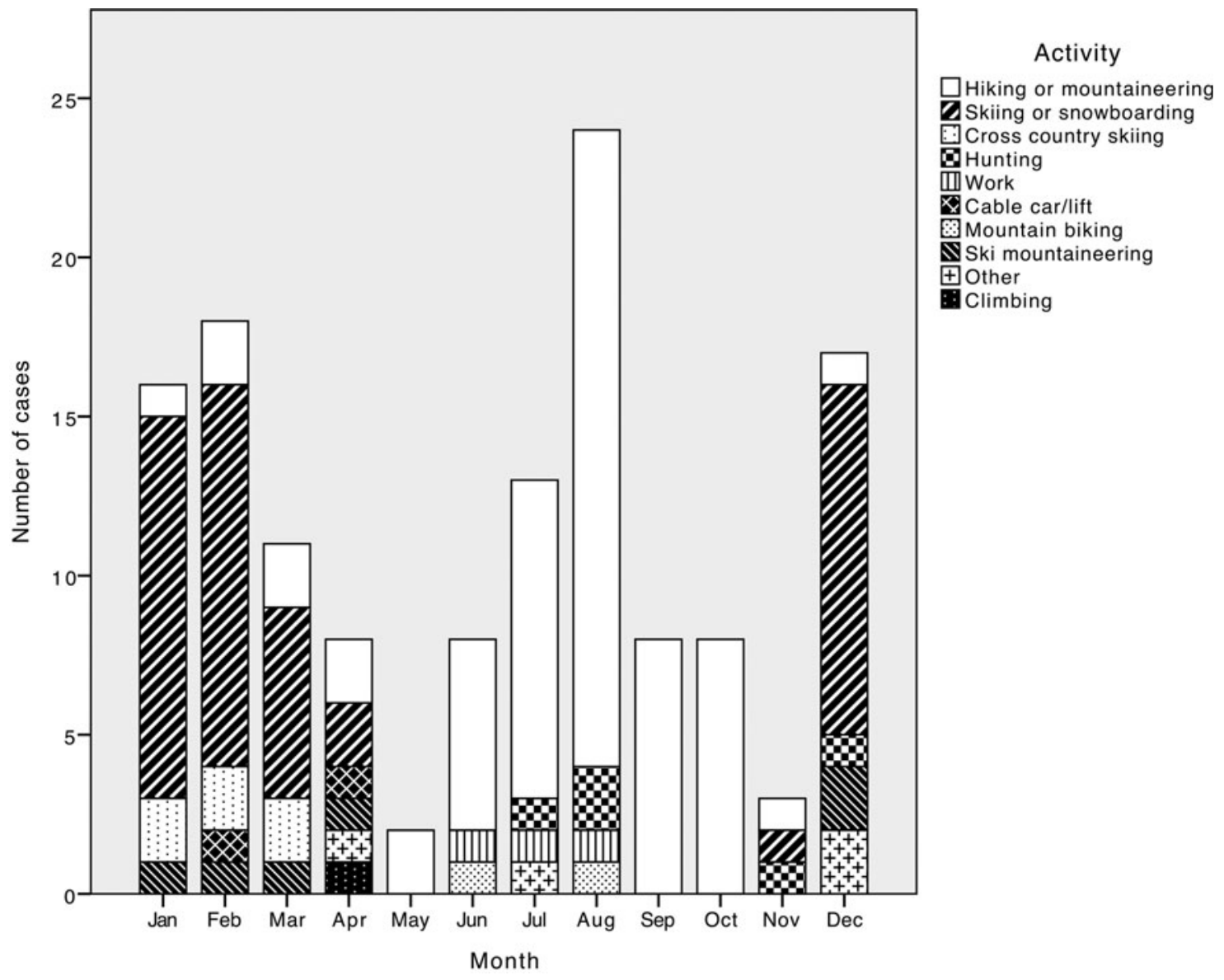

FIG. 3. Distribution of CPR performed in the Austrian Alps throughout the year and activity performed at the time of cardiac arrest.

performed by laypersons on site before the arrival of a professional rescue team. All patients who survived with good neurological outcome had a shockable rhythm on the first electrocardiogram. Table 2 summarizes the most important parameters of the eight identified cases of CPR with AED use in the Austrian Alps.

\section{Discussion}

This is the first study assessing CPR with AED use in the Austrian mountains. Before this study, only six cases of successful CPR using AED in mountain areas had been reported worldwide (Lienhart et al., 2005, 2006; Boehringer and Tilney, 2015; Yanagawa et al., 2017). Our analysis showed that CPR with AED use is occasionally performed in the Austrian mountains. The Austrian Alpine Police database is Europe's largest digital database for mountain accident research. Every year, information on $\sim 7000$ fatal and nonfatal accidents involving 10,000-11,000 persons is stored in this register (Sterr, 2016). The details and information on the individual accidents are taken from the records of the Alpine Police, which, as part of the Austrian Federal Police, is assigned to accidents in alpine terrain and records accidents to allow later investigation by the prosecutor's office and administrative authorities.

The serious life threat posed by sudden cardiac arrest is evident from the low survival rate in the nationwide database of only $4(3 \%)$ patients. In our study, all survivors received immediate CPR with AED. This study highlights the fact that even in mountain areas, immediate bystander CPR and the rapid use of an AED are essential for survival with good neurological outcome. Only $17 \%$ of cardiac arrest patients in the mountains in Austria received bystander CPR. This percentage was constant during the study period. The rate of bystander CPR is comparable to the rates in some urban areas (Bray et al., 2017). Cardiac arrest in mountain areas is a rare event that is very likely underreported. Thus, a retrospective epidemiological study model analyzing data from a registry is a good option for examining the incidence of cardiac arrest and the outcome of CPR with AED in the mountains.

An earlier published study analyzed 416 cases of sudden cardiac death in skiers and hikers (Burtscher et al., 1993); $90 \%$ occurred in men older than 34 years. Only a few victims were documented as having received CPR. That study found a 4.3-fold increased risk for male hikers older than 34 years and a 2.1-fold increased risk for male skiers older than 34 years to experience sudden cardiac arrest compared to the overall risk for sudden cardiac arrest; the risk for women was significantly lower.

Coronary artery disease is likely the main cause of exercise-related deaths, especially in men older than 40 years, who were not physically fit (Friedewald and Spence, 1990). Independent risk factors that increase the likelihood of sudden cardiac death are a previous heart attack, high blood 


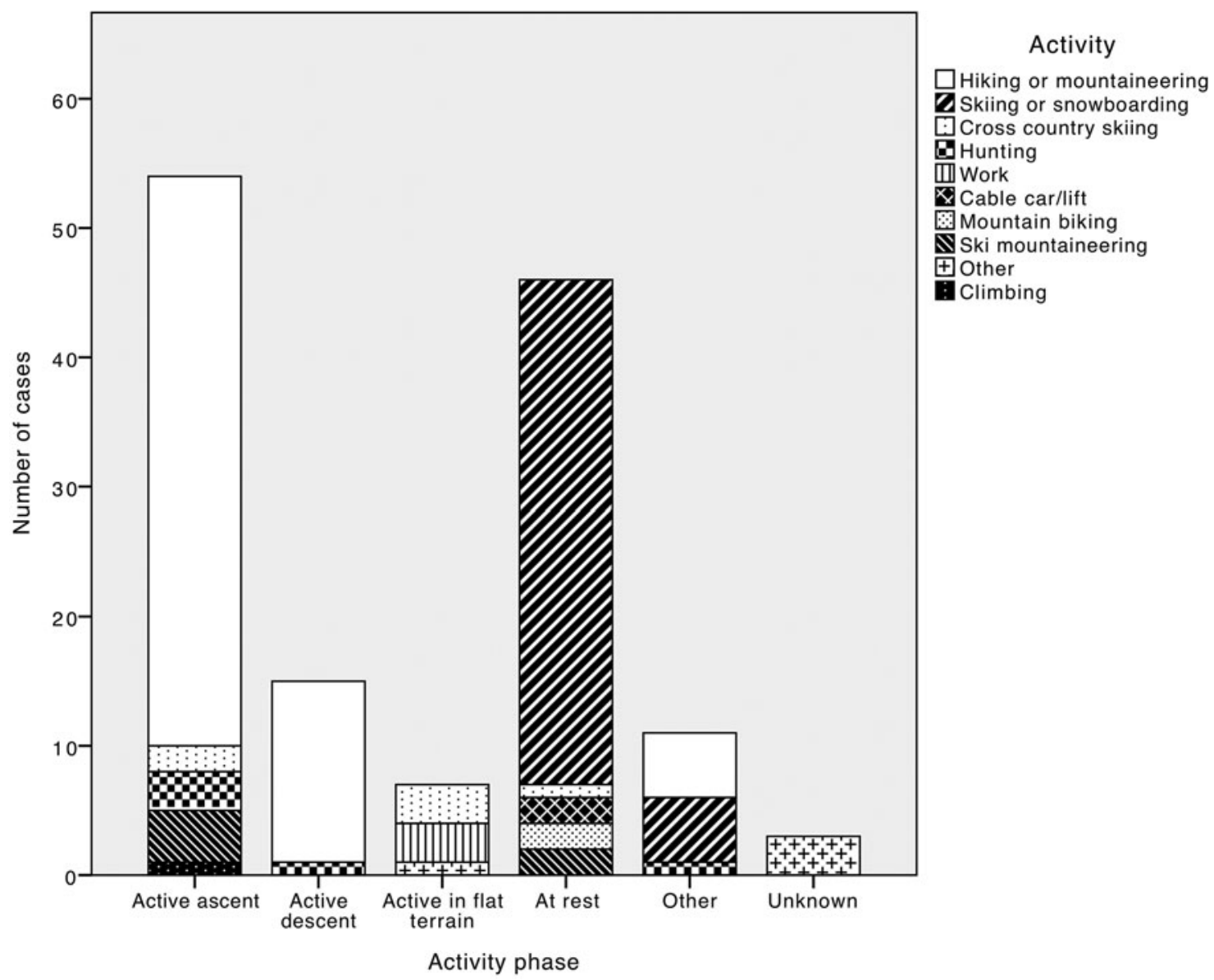

FIG. 4. Activity performed and activity phase at the time of cardiac arrest (in absolute terms).

pressure, diabetes mellitus, known cardiovascular disease, and elevated blood lipids. A previous study in the Austrian mountains showed that $13 \%$ of hikers and $11 \%$ of skiers have at least one of the abovementioned risk factors, which are more frequently found in men (15\% vs. $7 \%$ ) (Faulhaber et al., 2007). This may partly explain the higher incidence of sudden cardiac arrest in men.

The characteristics of the physical strain differ for the most common activities in the mountains, such as hiking, mountaineering, skiing, and snowboarding. Most cases of sudden cardiac arrest were associated with hiking and downhill skiing. Hiking induces a long-term continuous strain, while skiing requires short intense peaks of physical exertion (Burtscher et al., 2007). Sudden cardiac arrest occurred three times more often during the ascent than during the descent. The 2017 accident report of the German Alpine Club (DAV) found that the fatality rate for hiking or mountaineering is three to six times higher than for other mountain activities such as climbing or ski mountaineering (Randelzhofer, 2018). This could, of course, be related to the preponderance

Table 2. Survivors of Cardiac Arrest in Austrian Mountain Areas Who Received Cardiopulmonary Resuscitation and Treatment with an Automated External Defibrillator, and Who Were Treated AT THE INNSBRUCK UNIVERSITY HOSPITAL

\begin{tabular}{|c|c|c|c|c|c|c|c|c|c|c|}
\hline Age & Sex & Month & $\begin{array}{l}\text { Day of } \\
\text { the week }\end{array}$ & Time & Activity & $\begin{array}{l}\text { First rhythm } \\
\text { on ECG }\end{array}$ & $\begin{array}{c}\text { CPC at } \\
\text { discharge }\end{array}$ & $\begin{array}{l}\text { CPR lay } \\
\text { person }\end{array}$ & $\begin{array}{c}\text { Duration of } \\
\text { CPR (minutes) }\end{array}$ & Acute $C A G$ \\
\hline 72 & $\mathrm{~F}$ & Sep & Saturday & $11: 47$ & Hiking & VF & 2 & Yes & 20 & No \\
\hline 68 & $\mathrm{~F}$ & Jun & Thursday & $14: 30$ & Hiking & VF & 1 & Yes & 10 & No (6th day) \\
\hline 40 & $\mathrm{M}$ & Mar & Thursday & $12: 00$ & Skiing & VF & 1 & Yes & Not known & Yes \\
\hline 78 & $\mathrm{~F}$ & Sep & Wednesday & $12: 40$ & Hiking & VF & 2 & Yes & $<40$ & Yes \\
\hline 52 & $\mathrm{M}$ & May & Saturday & $10: 00$ & Hiking & Nonshockable & 4 & Yes & 40 & Yes \\
\hline 72 & $\mathrm{M}$ & Jan & Monday & $12: 40$ & Skiing & Shockable & 1 & Yes & 30 & Yes \\
\hline 66 & M & Jan & Thursday & $12: 48$ & Skiing & Asystole & 5 & Yes & 33 & Yes \\
\hline 85 & $\mathrm{~F}$ & Jan & Wednesday & $11: 30$ & Skiing & Nonshockable & 4 & Yes & 48 & Yes \\
\hline
\end{tabular}

Shockable rhythm means VF or pulseless ventricular tachycardia, nonshockable is any other rhythm.

CAG, coronary angiography; CPR, cardiopulmonary resuscitation; ECG, electrocardiography; F, female; M, male; VF, ventricular fibrillation. 
of older, less fit persons who were hiking or mountaineering compared to climbing and ski mountaineering.

The low survival rate in our study shows that survival is more unlikely in mountain areas than in some urban areas, where survival rates may be as high as $19 \%$ (Seattle/Greater King County) or 12\% (Vienna, Austria) (Schober et al., 2016; Geri et al., 2017). The most important factor for successful defibrillation is the earliest possible initiation of CPR, namely within 5 minutes after cardiac arrest (Strohle et al., 2014). The shorter the duration of CPR (Lienhart et al., 2005) and the sooner an AED is used, the greater the likelihood of surviving cardiac arrest without brain damage (van Alem et al., 2004). In our study, only patients who had received early CPR with an AED survived and had good neurological outcome.

Our findings support the notion that, comparable to urban areas, AED use in the mountains can improve survival from cardiac arrest if CPR is started immediately (Elsensohn et al., 2006). Due to the long response time for emergency medical services in mountain areas, some have suggested that CPR should consist of both chest compressions and rescue breaths to provide sufficient oxygen (Wallner et al., 2018). One strategy would be to perform chest-compression-only CPR for 5-8 minutes, and then start rescue breathing if the patient is still in cardiac arrest. Our study supports the current recommendations made by the European Resuscitation Council and ICAR MEDCOM on the placement of AEDs at specific sites, such as ski areas and mountain huts (Elsensohn et al., 2006; Truhlář et al., 2015).

\section{Limitations}

Only one case of CPR with AED use identified from the Alpine Police database was able to be assigned to the corresponding case in the Innsbruck Medical University Hospital information system. For two patients who suffered sudden cardiac arrest in Tyrol, the in-hospital treatment could not be identified. The search query in the hospital information system revealed seven cases of patients who had been resuscitated with AED in Austria's mountains, but who did not appear in the Alpine Police database. The current system of recording and documenting conducted by the Alpine Police itself must be seen as a limitation. Helicopter emergency medical service crew operations sometimes do not report cases of cardiac arrest to the Alpine Police if second-party liability can be excluded and no official investigations are needed. Furthermore, there is a lack of electronic coordination between the Alpine Police database and the national health care system.

Restrictions imposed by the Austrian Data Protection Authority made it impossible to analyze data from other Austrian hospitals potentially treating patients who had been resuscitated in the Austrian mountains. On the other hand, we found that a large proportion (69\%) of sudden cardiac arrest occurred in Austria's western states, which is probably due to the high concentration of mountain tourists there (Burtscher et al., 2001). Therefore, it can be assumed that a large percentage of patients who suffered a sudden cardiac arrest in the Austrian mountains were transferred to Innsbruck Medical University Hospital, which is the referral center for western Austria.

All patients resuscitated and transferred to Innsbruck Medical University Hospital had been immediately treated at the scene of the incident. In some of the cases, CPR had been initiated by medical personnel, who had been there by chance. This could cause a treatment bias, in that, it might have influenced helicopter emergency medical service crews to more often transfer such patients to a higher level care center than to a closer hospital with a lower level of care.

\section{Conclusions}

In the Austrian mountains, CPR was attempted in $<20 \%$ of sudden cardiac arrest cases. The few that survived had received immediate CPR with an AED. To better understand the circumstances and outcome of sudden cardiac arrest in the mountains, out-of hospital and in-hospital data should be linked.

\section{Acknowledgments}

We would like to thank Andreas Würtele and Dagmar Walter of the Register of the Austrian Alpine Safety Board (Austrian Alpine Police database) and Hans Ebner of the Austrian Alpine Police, as well as all the police officers who contributed data for the study.

\section{Authors' Contributions}

M.S., S.R., H.B., and P.P. conceptualized and designed the study. M.S. and P.N. extracted and analyzed the data; M.S., P.N., A.V., H.B., and P.P. made major contributions in writing the article. All authors read, approved, and revised the article.

\section{Author Disclosure Statement}

No competing financial interests exist.

\section{Funding Information}

No funding was received for this article.

\section{Supplementary Material}

Supplementary Data

\section{References}

Ajam K, Gold LS, Beck SS, Damon S, Phelps R, and Rea TD. (2011). Reliability of the cerebral performance category to classify neurological status among survivors of ventricular fibrillation arrest: A cohort study. Scand J Trauma Resusc Emerg Med 19:38.

Boehringer BK, and Tilney PV. (2015). An elderly man in cardiac arrest on a ski slope. Air Med J 34:62-64, 68.

Bray JE, Straney L, Smith K, Cartledge S, Case R, Bernard S, and Finn J. (2017). Regions with low rates of bystander cardiopulmonary resuscitation (CPR) have lower rates of CPR training in Victoria, Australia. J Am Heart Assoc 6: e005972.

Brugger H, Durrer B, Elsensohn F, Paal P, Strapazzon G, Winterberger E, Zafren K, Boyd J, and Icar M. (2013). Resuscitation of avalanche victims: Evidence-based guidelines of the international commission for mountain emergency medicine (ICAR MEDCOM): intended for physicians and other advanced life support personnel. Resuscitation 84:539546.

Burtscher M, Bachmann O, Hatzl T, Hotter B, Likar R, Philadelphy M, and Nachbauer W. (2001). Cardiopulmonary and metabolic responses in healthy elderly humans during a 1- 
week hiking programme at high altitude. Eur J Appl Physiol 84:379-386.

Burtscher M, Pachinger O, Schocke MF, and Ulmer H. (2007). Risk factor profile for sudden cardiac death during mountain hiking. Int J Sports Med 28:621-624.

Burtscher M, Philadelphy M, and Likar R. (1993). Sudden cardiac death during mountain hiking and downhill skiing. N Engl J Med 329:1738-1739.

Edgren E, Hedstrand U, Kelsey S, Sutton-Tyrrell K, and Safar P. (1994). Assessment of neurological prognosis in comatose survivors of cardiac arrest. BRCT I Study Group. Lancet 343: 1055-1059.

Elsensohn F, Agazzi G, Syme D, Swangard M, Facchetti G, Brugger $\mathrm{H}$, and International Commission for Mountain Emergency M. (2006). The use of automated external defibrillators and public access defibrillators in the mountains: Official guidelines of the international commission for mountain emergency medicine ICAR-MEDCOM. Wilderness Environ Med 17:64-66.

Faulhaber M, Flatz M, Gatterer H, Schobersberger W, and Burtscher M. (2007). Prevalence of cardiovascular diseases among alpine skiers and hikers in the Austrian Alps. High Alt Med Biol 8:245-252.

Friedewald VE Jr., and Spence DW. (1990). Sudden cardiac death associated with exercise: The risk-benefit issue. Am J Cardiol 66:183-188.

Geri G, Fahrenbruch C, Meischke H, Painter I, White L, Rea TD, and Weaver MR. (2017). Effects of bystander CPR following out-of-hospital cardiac arrest on hospital costs and long-term survival. Resuscitation 115:129-134.

Hackett PH, and Roach RC. (2001). High-altitude illness. N Engl J Med 345:107-114.

Kottmann A, Blancher M, Pasquier M, and Brugger $\mathrm{H}$. (2017). Avalanche victim resuscitation checklist adaption to the 2015 ERC resuscitation guidelines. Resuscitation 113:e3-e4.

Lienhart H, Knauer M, Bach D, and Wenzel V. (2006). [Successful resuscitation after rapid defibrillation by ski slope maintenance personnel. A case report]. Anaesthesist 55:41-44.

Lienhart HG, Breitfeld L, and Voelckel WG. (2005). [Public access defibrillation in alpine skiing areas: Three case reports and a brief survey of the literature]. Anasthesiol Intensivmed Notfallmed Schmerzther 40:150-155.

Nichols M, Townsend N, Scarborough P, and Rayner M. (2013). Cardiovascular disease in Europe: Epidemiological update. Eur Heart J 34:3028-3034.

Perkins GD, Handley AJ, Koster RW, Castren M, Smyth MA, Olasveengen T, Monsieurs KG, Raffay V, Grasner JT, Wenzel V, et al. (2015). European resuscitation council guidelines for resuscitation 2015: Section 2. Adult basic life support and automated external defibrillation. Resuscitation 95:81-99.

Randelzhofer P. (2018). Bergunfallstatistik 2016/2017. Alpenverein.de. Available at: https://www.alpenverein.de/chameleon/ public/c3a9d36a-4393-cae9-a189-bc7031152944/Bergunfall statistik-2016-2017_30772.pdf (accessed July 4, 2019).

Schober A, Sterz F, Laggner AN, Poppe M, Sulzgruber P, Lobmeyr E, Datler P, Keferbock M, Zeiner S, Nuernberger A, et al. (2016). Admission of out-of-hospital cardiac arrest victims to a high volume cardiac arrest center is linked to improved outcome. Resuscitation 106:42-48.

Sterr R. (2016). Österreichisches Kuratorium für alpine Sicherheit. Sommerbilanz 2016. Innsbruck 2016 [Internet]. Available at: www.alpinesicherheit.at/data/docs/bericht_pk\%20sommer\%20 2016.pdf (accessed July 4, 2019).

Strohle M, Paal P, Strapazzon G, Avancini G, Procter E, and Brugger H. (2014). Defibrillation in rural areas. Am J Emerg Med 32:1408-1412.

Truhlář A, Deakin CD, Soar J, Khalifa GEA, Alfonzo A, Bierens JJLM, Bratteb $\varnothing$ G, Brugger H, Dunning J, HunyadiAntičević S, Koster RW, Lockey DJ, Lott C, Paal P, Perkins GD, Sandroni C, Thies K-C, Zideman DA, and Nolan JP. (2015). Cardiac arrest in special circumstances [in Italian]. Resuscitation 95:148-201.

van Alem AP, Waalewijn RA, Koster RW, and de Vos R. (2004). Assessment of quality of life and cognitive function after out-of-hospital cardiac arrest with successful resuscitation. Am J Cardiol 93:131-135.

Wallner B, Brugger H, Ellerton J, and Paal P. (2018). In mountain and rural areas all CPR providers should perform chest compressions and rescue breaths for patients in cardiac arrest. Resuscitation 127:e5.

Yanagawa Y, Omori K, Takeuchi I, Jitsuiki K, Yoshizawa T, Ishikawa K, Kando Y, Fukata M, and Ohsaka H. (2017). Cardiac arrest at high elevation with a favorable outcome. Am J Emerg Med 35:661.e5-661.e7.

Address correspondence to: Anna Vögele, MD Institute of Mountain Emergency Medicine EURAC Research Via Ipazia 1 Bolzano 39100 Italy

E-mail: anna.voegele@eurac.edu

Received November 20, 2018; accepted in final form August 1, 2019. 